\title{
TESTING FOR FINANCIAL CONTAGION BETWEEN DEVELOPED AND \\ EMERGING MARKETS DURING THE 1997 EAST ASIAN CRISIS
}

\author{
Philip Arestis \\ University of Cambridge \\ Guglielmo Maria Caporale \\ Brunel University, London \\ Andrea Cipollini \\ Queen Mary, University of London \\ Nicola Spagnolo \\ Brunel University, London
}

April 2005

\begin{abstract}
In this paper we examine whether during the 1997 East Asian crisis there was any contagion from the four largest economies in the region (Thailand, Indonesia, Korea and Malaysia) to a number of developed countries (Japan, UK, Germany and France). Following Forbes and Rigobon (2002), we test for contagion as a significant positive shift in the correlation between asset returns, taking into account heteroscedasticity and endogeneity bias. Furthermore, we improve on earlier empirical studies by carrying out a full sample test of the stability of the system that relies on more plausible (over)identifying restrictions. The estimation results provide some evidence of contagion, in particular from Japan (the major international lender in the region), which drastically cut its credit lines to the other Asian countries in 1997.
\end{abstract}

Keywords: Contagion, Financial Crises, Conditional Correlation

JEL Classification: F30, G15

Corresponding author: Professor Guglielmo Maria Caporale, Brunel Business School, Brunel University, Uxbridge, Middlesex UB8 3PH, UK. Tel.: +44 (0)1895 266713. Fax: +44 (0)1895 269770. Email: Guglielmo-Maria.Caporale@brunel.ac.uk 


\section{Introduction}

Before the 1990s, financial crises were seen as events only affecting the country in which they had originally occurred. However, the financial crises of 1994-5 in Mexico, 1997-8 in East Asia, and 1998 in Russia spread rapidly beyond the countries where they had originated to others with different economic structures and institutions. This paper focused on establishing whether 'contagion' took place in the case of the 1997-98 East Asian crisis, more precisely between the financial systems of the four largest economies in the region, i.e. Thailand, Indonesia, Korea and Malaysia, and those of the main international lenders, i.e. Japan, Germany, France and UK. ${ }^{1}$

Following King and Wadhwani (1990), we define contagion as a significant increase in cross-market linkages after a shock to one country, and also correct for heteroscedasticity and endogeneity bias as suggested by Forbes and Rigobon (2002), and Rigobon (2004), respectively. ${ }^{2}$ Furthermore, in order to determine endogenously the breakpoints denoting the contagion period, we employ the sequential dummy test introduced by Caporale et al (2005) that relies on more plausible (over) identifying restrictions compared to earlier studies. Finally, as in the latter study, we compute the appropriate critical values for this test by means of bootstrap.

The layout of the paper is as follows. Section 2 reviews the literature on tests of financial contagion based upon conditional correlation analysis and outlines the empirical methodology. Section 3 presents the empirical results. Section 4 summarises the main findings and offers some concluding remarks along with a number of policy implications to improve the containment of contagion spreading.

\footnotetext{
${ }^{1}$ These four countries are by far the main international lenders to the East Asian countries examined in this paper. This is the reason why the US has been left out of our sample of developed countries, the four included being more relevant to the analysis carried out in our study.

${ }^{2}$ It ought to be noted that there is no general consensus among economists on the definition of contagion. Pericoli and Sbracia (2003) provide a critical review of the theoretical and empirical literature, with different definitions of contagion.
} 


\section{Correlation Analysis of Financial Contagion}

\subsection{A brief review of the literature}

The test for contagion adopted in this paper is based upon a conditional correlation analysis. In other words, a parameter stability test on the coefficient describing the relationship between asset returns is used to test the null of interdependence against the alternative of contagion. In their seminal study, King and Wadhwani (1990) were the first to measure contagion as a significant increase in the correlation between assets returns. Specifically, they analysed the correlation between US, UK and Japanese equities returns around the time of the 1987 stock market crash, and found that the degree of correlation increased after October 1987. There followed a vast empirical literature on this type of test for contagion, which has been discussed extensively elsewhere (see, e.g., Forbes and Rigobon, 1999). ${ }^{3}$ Recently, Rigobon (2004) has pointed out that tests for contagion based on conditional correlation analysis have serious limitations. In particular, parameter stability tests using high-frequency financial series suffer from heteroscedasticity, endogeneity and omitted variables bias. Consider the structural form system:

$$
A_{0} Y_{t}=A_{1} D Y_{t}+\Gamma z_{t}+\varepsilon_{t}
$$

where $Y_{t}=\left[y_{1 t}, y_{2 t}\right]^{\prime}$ is a vector of two (demeaned) endogenous variables (countryspecific asset returns) at time $t$. In particular, in this paper, $\mathrm{y}_{1}$ and $\mathrm{y}_{2}$ correspond to asset returns in an East Asian emerging market and a developed country, respectively. The components of the vector $v_{t}=\left[\varepsilon_{t}, \eta_{t}\right]^{\prime}$ are structural form idiosyncratic shocks. Furthermore, the vector $D Y_{t}$, which captures (deterministic) shifts in the slope coefficients associated with the endogenous variables, is given stochastic regressors $D_{2 t}$ and $D_{1 t}$, that is:

\footnotetext{
${ }^{3}$ Dungey et al. (2004a) utilise a unifying framework that enables them to examine the similarities and differences of the various empirical studies of contagion in financial markets. A companion paper (Dungey et al., 2004b) discusses the implementation of the tests described in Dungey et al. (2004a), and also deals
} 
$D Y_{t}=\left[\begin{array}{l}D_{2 t} \\ D_{1 t}\end{array}\right]$

The regressors $D_{2 t}$ and $D_{1 t}$ are obtained, respectively by multiplying the time series $y_{2 t}$ in (1) by a dummy variable taking value 1 when there is contagion from country $y_{2}$ to country $y_{1}$ and 0 elsewhere, and the time series $y_{1 t}$ by a dummy variable taking value 1 when there is contagion from country $y_{1}$ to country $y_{2}$ and 0 elsewhere. We use the 3 month US Treasury bill as a proxy for the common shock $z_{t}$, in order to capture the effect of common monetary policy shifts here identified as shifts in the US Federal Reserve policy ${ }^{4}$.

The coefficient matrices in (1) have the following specification:

$$
A_{0}=\left[\begin{array}{cc}
1 & -\beta_{0} \\
\alpha_{0} & 1
\end{array}\right] ; A_{1}=\left[\begin{array}{cc}
\beta_{1} & 0 \\
0 & \alpha_{1}
\end{array}\right] ; \Gamma=\left[\begin{array}{l}
\gamma \\
1
\end{array}\right]
$$

A statistically significant and positive $\beta_{1}$ suggests contagion from the developed country to the emerging market. Evidence of contagion in the opposite direction is indicated by a statistically significant and positive $\alpha_{1}$. In particular, In line with Forbes and Rigobon (2002), it is important to note that the test for the null of interdependence versus the alternative of (shift) contagion is one-sided (given that, under the alternative of contagion, we expect $\alpha_{1}$ and, or $\beta_{1}$ to be positive $)^{5}$.

Given the structural form system in (1), the reduced form shocks are given by:

$$
\begin{aligned}
& \omega_{1 t}=\frac{1}{\left(1-\alpha_{0} \beta_{0}\right)}\left[\beta_{1} * D_{2 t}+\beta_{0} \alpha_{1} D_{1 t}+\left(\gamma+\beta_{0}\right) z_{t}+\left(\varepsilon_{t}+\beta_{0} \eta_{t}\right)\right] \\
& \omega_{2 t}=\frac{1}{\left(1-\alpha_{0} \beta_{0}\right)}\left[\alpha_{0} \beta_{1} * D_{2 t}+\alpha_{1} D_{1 t}+\left(\alpha_{0} \gamma+1\right) z_{t}+\left(\alpha_{0} \varepsilon_{t}+\eta_{t}\right)\right]
\end{aligned}
$$

with a number of issues such as data frequency, missing observations, endogenous definitions of the periods of crisis.

${ }^{4}$ The use of interest rates as a proxy of $z_{t}$ is advocated, for instance, by Rigobon (2003). More recently, Rigobon (2004) has treated the common shock as a latent variable. 
From eq. (2) we can obtain the unconditional second moments for the reduced form innovations:

$$
\left(\begin{array}{c}
E\left(\omega_{1}\right)^{2} \\
E\left(\omega_{1} \omega_{2}\right) \\
E\left(\omega_{2}\right)^{2}
\end{array}\right)=\frac{1}{\left(1-\alpha_{0} \beta_{0}\right)^{2}}\left[\left(\begin{array}{cc}
\beta_{0}^{2} & 1 \\
\beta_{0} & \alpha_{0} \\
1 & \alpha_{0}^{2}
\end{array}\right)\left(\begin{array}{c}
\varsigma_{\eta} \\
\varsigma_{\varepsilon}
\end{array}\right)+\left(\begin{array}{c}
\left(\gamma+\beta_{0}\right)^{2} \\
\left(\gamma+\beta_{0}\right)\left(\alpha_{0} \gamma+1\right) \\
\left(\alpha_{0} \gamma+1\right)^{2}
\end{array}\right)+\left(\begin{array}{c}
\beta_{0}^{2} \alpha_{1}^{2} \\
\beta_{0} \alpha_{1}^{2} \\
\alpha_{1}^{2}
\end{array}\right)+\left(\begin{array}{c}
\beta_{1}^{2} \\
\alpha_{0} \beta_{1}^{2} \\
\alpha_{0}^{2} \beta_{1}^{2}
\end{array}\right)\right]
$$

where $E$ is the unconditional expectation operator, $\zeta_{\eta}$ and $\zeta_{\varepsilon}$ are the unconditional variances of the structural form innovations, and the unconditional variances for $z_{t}, D_{1 t}$ and $D_{2 t}$ are assumed to be equal to unity. From equation (3), it can be seen that the unconditional covariance matrix for the reduced form shocks gives three equations, whereas there are seven unknowns: $\alpha_{0}, \alpha_{1}, \beta_{0}, \beta_{1}, \gamma, \zeta_{\eta}$ and $\zeta_{\varepsilon}$. It follows that the system in (1) is not identified. The identification method suggested by Rigobon (2004) is based upon the heteroscedastic time series properties of the variables under investigation. However, this method, by relying on switches in the unconditional variances of the structural form shocks, can identify a simultaneous equation system with shifts in the slope coefficients only if the number of regime shifts in the second moments is equal to or greater than five. Therefore, it requires the detection of at least four breakpoints for the second moments. The recent empirical literature on contagion based upon conditional correlation analysis relies on the assumption of only two regime shifts in the unconditional variances (associated with a tranquil and a turmoil period, respectively). Consequently, some additional restrictions have to be imposed to identify the system in (1). The first assumption (see the studies below) consists in considering the common shock $z_{t}$ as a predetermined variable (hence, it is implicitly assumed that $\gamma$ equals to zero). In Forbes and Rigobon (2002), and Baig and Goldfain (1998), there is also a zero exclusion restriction on one of the two slope coefficients in order to test for contagion. ${ }^{6}$

\footnotetext{
${ }^{5}$ The DCC statistic proposed by Rigobon (2003) to test for contagion is two-sided.

${ }^{6}$ Forbes and Rigobon (2002) propose a correction for heteroscedasticity bias affecting the parameter stability test on the correlation coefficient. Their empirical analysis (based upon the returns in 36 emerging markets) suggests little evidence of contagion (see also Baig and Goldfain, 1998 for similar results).
} 
Rigobon (2003) relies also on the assumption of switches in the unconditional variance of only one of the two shocks. ${ }^{7}$

An alternative method for system identification is based on considering switches in the conditional variances. More specifically, Rigobon (2002) shows how to identify a structurally stable system (without a common shock) employing a Multivariate GARCH specification for the conditional variances of the structural form innovations. Our contribution, outlined in the next section, consists in achieving identification of the system given by (1) by imposing restrictions on the specification for the Multivariate GARCH specification for the conditional second moments.

\subsection{Identification through GARCH}

The conditional forecasts for the second moments corresponding to the reduced form residuals in (2) are given by:

$$
\begin{aligned}
& \left(\begin{array}{c}
h_{\omega 1, t} \\
h_{\omega 12, t} \\
h_{\omega 2}, t
\end{array}\right)=\frac{1}{\left(1-\alpha_{0} \beta_{0}\right)^{2}}\left[\begin{array}{cc}
1 & \beta_{0}^{2} \\
\alpha_{0} & \beta_{0} \\
\alpha_{0}^{2} & 1
\end{array}\right]\left(\begin{array}{l}
h_{g t} \\
h_{\eta t}
\end{array}\right)+\frac{1}{\left(1-\alpha_{0} \beta_{0}\right)^{2}}\left[\begin{array}{c}
\left(\gamma+\beta_{0}\right)^{2} \\
\left(\gamma+\beta_{0}\right)\left(\alpha_{0} \gamma+1\right) \\
\left(\alpha_{0} \gamma+1\right)^{2}
\end{array}\right] h_{z t} \\
& +\frac{1}{\left(1-\alpha_{0} \beta_{0}\right)^{2}}\left[\begin{array}{c}
\left(\beta_{0}^{2} \alpha_{1}^{2}\right) \\
\beta_{0} \alpha_{1}^{2} \\
\alpha_{1}^{2}
\end{array}\right] h_{D 1}+\frac{1}{\left(1-\alpha_{0} \beta_{0}\right)^{2}}\left[\begin{array}{c}
\left(\beta_{1}^{2}\right) \\
\alpha_{0} \beta_{1}^{2} \\
\alpha_{0}^{2} \beta_{1}^{2}
\end{array}\right] h_{D 2}
\end{aligned}
$$

If we assume $h_{z t}, h_{D 1}, h_{D 2}$ equal to unity, and a multivariate GARCH specification for conditional forecasts of the second moments for the structural form shocks ${ }^{8}$ :

$$
\left(\begin{array}{l}
h_{\varepsilon t} \\
h_{\eta t}
\end{array}\right)=\left(\begin{array}{l}
\varsigma_{\varepsilon} \\
\varsigma_{\eta}
\end{array}\right)+\left[\begin{array}{ll}
\lambda_{\varepsilon \varepsilon} & \lambda_{\varepsilon \eta} \\
\lambda_{\eta \varepsilon} & \lambda_{\eta \eta}
\end{array}\right]\left(\begin{array}{c}
\varepsilon_{t-1}^{2} \\
\eta_{t-1}^{2}
\end{array}\right)+\left[\begin{array}{ll}
\gamma_{\varepsilon \varepsilon} & \gamma_{\varepsilon \eta} \\
\gamma_{\eta \varepsilon} & \gamma_{\eta \eta}
\end{array}\right]\left(\begin{array}{l}
h_{\varepsilon, t-1} \\
h_{\eta, t-1}
\end{array}\right)
$$

\footnotetext{
${ }^{7}$ Note that the Determinant of the Change in Covariance matrix test (DCC) employed by Rigobon (2003) is two-sided, given that the alternative hypothesis implies shifts in either direction of the slope coefficient. Using the DCC test, he finds some evidence of contagion between the East Asian countries during the 1997 crisis.
} 
then, by replacing (5) in (4), we obtain eq. (6):

$$
\begin{aligned}
& \left(\begin{array}{c}
h_{\omega 1, t} \\
h_{\omega 12, t} \\
h_{\omega 2, t}
\end{array}\right)=\frac{1}{\left(1-\alpha_{0} \beta_{0}\right)^{2}}\left[\left(\begin{array}{cc}
\beta_{0}^{2} & 1 \\
\beta_{0} & \alpha_{0} \\
1 & \alpha_{0}^{2}
\end{array}\right)\left(\begin{array}{c}
\varsigma_{\eta} \\
\varsigma_{\varepsilon}
\end{array}\right)+\left(\begin{array}{c}
\left(\gamma+\beta_{0}\right)^{2} \\
\left(\gamma+\beta_{0}\right)\left(\alpha_{0} \gamma+1\right) \\
\left(\alpha_{0} \gamma+1\right)^{2}
\end{array}\right)+\left(\begin{array}{c}
\beta_{0}^{2} \alpha_{1}^{2} \\
\beta_{0} \alpha_{1}^{2} \\
\alpha_{1}^{2}
\end{array}\right)+\left(\begin{array}{c}
\beta_{1}^{2} \\
\alpha_{0} \beta_{1}^{2} \\
\alpha_{0}^{2} \beta_{1}^{2}
\end{array}\right)\right]+ \\
& \frac{1}{\left(1+\alpha_{0} \beta_{0}\right)^{2}}\left[\begin{array}{cc}
\left(\beta_{0}^{2} \lambda_{\eta \varepsilon}+\lambda_{\varepsilon \varepsilon}\right)+\left(\beta_{0}^{2} \lambda_{\eta \varepsilon}+\lambda_{\varepsilon \varepsilon}\right) & \beta_{0}^{2}\left(\beta_{0}^{2} \lambda_{\eta \varepsilon}+\lambda_{\varepsilon \varepsilon}\right)+\left(\beta^{2} \lambda_{\eta \eta}+\lambda_{\varepsilon \eta}\right) \\
\left(\beta_{0} \lambda_{\eta \varepsilon}+\alpha_{0} \lambda_{\varepsilon \varepsilon}\right)+\alpha_{0}^{2}\left(\beta_{0} \lambda_{\eta \eta}+\alpha_{0} \lambda_{\varepsilon \eta}\right) & \beta_{0}^{2}\left(\beta_{0}^{2} \lambda_{\eta \varepsilon}+\alpha_{0} \lambda_{\varepsilon \varepsilon}\right)+\beta_{0}\left(\lambda_{\eta \eta}+\alpha_{0} \lambda_{\varepsilon \eta}\right) \\
\beta_{0}^{2}\left(\lambda_{\eta \varepsilon}+\alpha_{0}^{2} \lambda_{\varepsilon \varepsilon}\right)+\alpha_{0}^{2}\left(\lambda_{\eta \eta}+\alpha_{0}^{2} \lambda_{\varepsilon \eta}\right) & \beta_{0}^{2}\left(\lambda_{\eta \varepsilon}+\alpha_{0}^{2} \lambda_{\varepsilon \varepsilon}\right)+\left(\lambda_{\eta \eta}+\alpha_{0}^{2} \lambda_{\varepsilon \eta}\right)
\end{array}\right]\left(\begin{array}{c}
\omega_{1 t-1}^{2} \\
\omega_{2 t-1}^{2}
\end{array}\right)+
\end{aligned}
$$

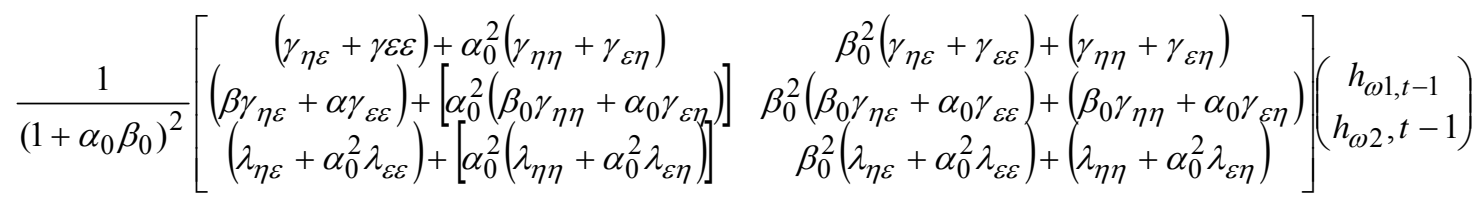

The coefficient matrices (each of dimension $3 \times 2$ ) in last two addends provide 12 equations, containing 13 unknowns (eight from the multivariate GARCH specification for the conditional variance, and five from the conditional mean). Therefore, we assume zero volatility spillovers among the structural form shocks (e.g. $\lambda_{\varepsilon \eta}=\lambda_{\eta \varepsilon}=\gamma_{\varepsilon \eta}=\gamma_{\eta \varepsilon}=0$ ) in order to (over) identify the simultaneous equation system given by (1) and (5).

It is important to observe that, in the aforementioned studies, the unknowns of the structural form system are estimated by GMM. This involves splitting the sample into a typically large 'non-crisis' and a small 'crisis' period. As shown by Dungey and Zhumabekova (2001), such tests have very low power, and extending the crisis sample period can change the inference altogether ${ }^{9}$. In this paper, as shown in equation (1), we use deterministic dummies in order to exploit the full sample information set. Moreover, the estimation of the structural form system given by (1) and by (5) imposing zero volatility spillovers is obtained through Quasi Maximum Likelihood. More specifically, assuming that the structural innovations are Gaussian, the conditional log-likelihood (ignoring a constant term) is:

\footnotetext{
${ }^{8}$ We are implicitily imposing the standard orthogonality condition among the structural form innovations for the purpose of identification.

${ }^{9}$ The study by Favero and Giavazzi (2000) is not subject to this critique, as they use the full sample to investigate whether there is any evidence of contagion within the ERM countries during the EMS crisis. Identification is obtained using zero exclusion restrictions on the lags for the conditional mean system.
} 


$$
L_{t}=-\frac{1}{2} \log \left|\Gamma_{t}\right|-\frac{1}{2} v_{t}^{\prime}\left(\Gamma_{t}\right)^{-1} v_{t}
$$

where $v_{t}$ is the vector of structural innovations. We maximise the joint $\log$-likelihood $\Sigma_{\mathrm{t}} \mathrm{L}_{\mathrm{t}}$ over the parameters of the conditional mean and variance equations by using the simplex algorithm in the first few iterations and then the BFGS algorithm.

Furthermore, as in Caporale et al (2005), in order to test for parameter instability in the conditional mean, we implement a one-tail test for the joint null $\mathrm{H}_{0}: \alpha_{1}=\beta_{1}=0$ (that is, interdependence) against the alternative of contagion from at least one country (e.g. at least one of the coefficients between $\alpha_{1}$ and $\beta_{1}$ is positive). For this purpose, we use the following Wald statistic:

$W=[R \hat{\theta}]^{\prime}\left[R \operatorname{Var}(\hat{\theta}) R^{\prime}\right]^{-1}[R \hat{\theta}]$

where $\mathrm{R}$ is the $q \times k$ matrix of restrictions, with $q$ equal to the number of restrictions and $k$ equal to the number of regressors; $\hat{\theta}$ are the estimated parameters, and $\operatorname{Var}(\hat{\theta})$ is the heteroscedasticity-robust consistent estimator for the covariance matrix of the parameter estimates.

Finally, we use a one-tail t-ratio statistic for the coefficients $\alpha_{1}$ and $\beta_{1}$ to test the null of interdependence against the alternative of contagion.

\subsection{Inference using bootstrapped critical values}

In the aforementioned studies the window separating different periods is chosen arbitrarily. In this paper we detect the breakpoint endogenously by employing a sequential dummy test. For this purpose, we considered a number of different specifications for the step dummy (e.g. we allow the starting date for contagion to range from January 1997 to June 1998) and we select the one with the largest Wald statistic. We conclude that there is evidence of contagion only if this statistic is significant and if 
the coefficients associated with the step dummies are positive and significant. ${ }^{10}$ In line with Caporale et al (2005), given that under the null of parameter stability (e.g., interdependence), the distribution of both the t-ratios and Wald statistics are unknown, we obtain the relevant critical values through bootstrapping. In particular, first we estimate, under the null of parameter stability, the system given by (1) and by (5) imposing zero volatility spillovers, that is:

$$
\begin{aligned}
& y_{1_{t}}=\alpha_{0} y_{2 t}+z_{t}+\varepsilon_{t} \\
& y_{2 t}=\beta_{0} y_{1 t}+\gamma_{t}+\eta_{t} \\
& h_{y 1 t}=\varsigma_{\varepsilon}+\gamma_{\varepsilon \varepsilon} h_{y 1, t-1}+\lambda_{\varepsilon \varepsilon} \varepsilon_{y 1, t-1}^{2} \\
& h_{y 2_{t}}=\varsigma_{\eta}+\gamma_{\eta \eta} h_{y 2, t-1}+\lambda_{\varepsilon \varepsilon} \varepsilon_{y 2, t-1}^{2}
\end{aligned}
$$

Given the estimated parameters $\hat{\alpha}_{0}, \hat{\beta}_{0}$ and $\hat{\gamma}$, and given the estimated residuals from (7), $\hat{\varepsilon}_{y_{1 t}}$ and $\hat{\varepsilon}_{y_{2 t}}$, the latter are re-sampled with replacement, generating the artificial series:

$$
\begin{aligned}
& \hat{y_{1 t}}=\hat{\alpha_{0}} \hat{y_{2 t}}+z_{t}+\hat{\varepsilon}_{y_{1 t}} \\
& \hat{y_{2 t}}=\hat{\beta_{0}} \hat{y}_{1 t}+\hat{\gamma} z_{t}+\hat{\varepsilon}_{y_{2 t}}
\end{aligned}
$$

Using the artificial series given by (9), we jointly estimate the following system:

$$
\begin{aligned}
& \hat{y}_{1 t}=\alpha_{0} \hat{y}_{2 t}+\alpha_{1} * D_{1 t} * \hat{y}_{2 t}+z_{t}+\eta_{y_{1 t}} \\
& \hat{y}_{2 t}=\beta_{0} \hat{y}_{1 t}+\beta_{1} * D_{2 t} * \hat{y}_{1 t}+\gamma z_{t}+\eta_{y_{2 t}} \\
& h_{y_{1 t}}=\left(1-\delta_{1}-\delta_{2}\right)+\delta_{1} h_{y_{1, t-1}}+\delta_{2} \eta_{y_{1, t-1}}^{2} \\
& h_{y_{2 t}}=\left(1-\delta_{3}-\delta_{4}\right)+\delta_{3} h_{y_{2, t-1}}+\delta_{4} \eta_{y_{2, t-1}}^{2}
\end{aligned}
$$

10 The identification scheme adopted here was supported empirically by the presence of conditional heteroscedasticity modelled as an Integrated Generalized Autoregressive Conditionally Heteroskedastic (IGARCH) structure. Finally, a Ljung-Box test on the squared standardised residuals shows no evidence of remaining heteroscedasticity. These results are available upon request. 
and then compute the Wald test statistic, corresponding to the breakpoint chosen as above. Repeating this exercise 1000 times, we are able to bootstrap the distribution of the Wald test statistic, thereby obtaining the 95\% empirical critical values. Having tested for the presence of a structural break (contagion), we assess whether the causality links during the crisis period are uni-directional or bi-directional, checking for the statistical significance of the estimated coefficients associated with each dummy by means of bootstrapped robust t-ratios.

\section{Empirical Analysis}

To test for financial contagion we use weekly stock returns for four developed countries (the major international lenders: Japan, Germany, UK and France), and for the four largest economies in the East Asian region, which were most heavily affected by the crisis (Thailand, Indonesia, Korea and Malaysia) ${ }^{11}$. The sample period goes from the first week of August 1990 to the last week of July 1998. This end date has been chosen in order to avoid any overlap with the Russian crisis of August 1998. The choice of the breakpoint, corresponding to the beginning of the contagion period, is obtained employing the sequential dummy test described above.

In Table 1 we report the exposure of the major international lenders to the four East Asian emerging market economies under investigation between the second semester of 1996 and the first semester of 1998. Our empirical findings are in line with those of Kaminsky and Reinhart (2001), who found that the drastic reduction in bank lending from the major international lenders had some contagious effect on the East Asian countries. Between the first semester of 1997 and the first semester of 1998, the developed countries reduced substantially their exposure toward the Asian region (see Table 1). In particular, by inspecting Table 2 and Table 3, it can be seen that, by the end of 1997, Japan (which had the largest exposure to the East Asian region) is the only developed economy to have contagious effects on each of the emerging markets under investigation. During the second semester of 1997 there is evidence of contagion from France to Indonesia (reflecting the fact that this developed economy was the only one to

\footnotetext{
${ }^{11}$ All series have been obtained from Datastream, and the package RATS was used for the computations.
} 
have significantly decreased its lending to Indonesia by the end of 1997), and also from Germany to Indonesia in the first semester of 1998 (when Germany decreased its lending toward this emerging market). Moreover, the empirical evidence indicates the presence of contagion not only from Japan, but also from France (the country which most abruptly cut its credit lines between the second semester of 1997 and the first semester of 1998) to Korea in April 1998.

Finally, in contrast to Forbes and Rigobon (2002) and to Rigobon (2003), we find some evidence of contagion from the East Asian countries to the developed ones. Specifically, there appears to have been contagion (during the second semester of 1997) from Indonesia to the UK. This developed country was heavily exposed to Indonesia, and it had cut only slightly its credit lines to this emerging country by the end of 1997 . There are also some contagious effects from Korea and Thailand to France, which had the largest exposure of all developed countries to these two emerging market economies, and from Thailand to the UK.

\section{Conclusions}

The main empirical finding of this paper is the existence of contagion between Japan and the four largest countries in East Asian region (Thailand, Indonesia, Malaysia, Korea) during the 1997-1998 crisis period. Following Forbes and Rigobon (2002) and Rigobon (2003), we have tested for contagion as a positive shift in the degree of co-movement between asset returns, taking into account heteroscedasticity and endogeneity bias. Moreover, we have improved upon their study by taking the approach advocated by Caporale et al (2005), which relies on more plausible (over)identifying restrictions by carrying out a full sample test for the stability of a structural form system. The estimation results show that the impact of the East Asian crisis on developed financial markets was small. Risk diversification through reallocation of bank loans, a substantial decrease of the exposure to East Asian countries on the part of Western and Japanese banks, and prudential supervision and regulation, reduced the impact of the East Asian crisis on the developed economies. By contrast, the drastic reduction of international lending in the last two quarters of 1997, especially from Japan (the country with the largest exposure 
toward the Asian region), had a significant contagious effect on the East Asian economies.

There are clear policy implications of our findings where contagion is evident. The importance of information disclosure by large international investors, improved standards and prudential controls in borrowing and lending, along with internationally coordinated regulations of hedge funds and other institutions that are highly leveraged, are the most obvious. In order to be successful, such policies should also be accompanied by effective regulation and supervision of financial systems to ensure prudent risk management on the part of banks and corporations. Even more importantly, relevant changes to the international financial architecture should be implemented to guarantee the success of these policy measures. 


\section{References}

Baig, T. and I. Goldfajn (1998), "Financial market contagion in the Asian crisis", International Monetary Fund, WP/98/155.

Basel Committee on Banking Supervision (1999) "Supervisory lessons to be drawn from the Asian crisis", BIS working paper no. 2.

Caporale, G.M., Cipollini, A. and N. Spagnolo (2005), "Testing for contagion: a conditional correlation analysis", Journal of Empirical Finance, forthcoming.

Dornbusch, R., Park, Y.C. and Claessens, S. (2000), "Contagion: Understanding How it Spreads", The World Bank Research Observer, 15(2), 177-197.

Dungey, M. and D. Zhumabekova (2001), "Testing for contagion using correlations: some words of caution", WP no. PB01-09, Center for Pacific Basin Monetary and Economic Studies, Economic Research Department, Federal Reserve Bank of San Francisco.

Dungey, M., R. Fry, B. Gonzalez-Hermosillo and V. Martin (2004a), "Empirical Modeling of Contagion: A Review of Methodologies", International Monetary Fund, $\mathrm{WP} / 04 / 78$.

Dungey, M., R. Fry, B. Gonzalez-Hermosillo and V. Martin (2004b), "A Comparison of Alternative Tests of Contagion with Applications", mimeo, Australian National University.

Favero, C.A. and F. Giavazzi (2000), "Looking for contagion: evidence from the ERM", NBER Working Paper no. 7797.

Forbes, K. J. and R. Rigobon (1999), "Measuring contagion: conceptual and empirical issues", MIT-Sloan School of Management, mimeo.

Forbes, K. and Rigobon, R. (2002), "No contagion, only interdependence", Journal of Finance, 57(5), 223-261.

Kaminsky, G. and Reinhart, C. M. (2001), "Bank lending and contagion: evidence from the Asian crisis" in T. Ito and A. Krueger, eds., Regional and Global Capital Flows: Macroeconomic Causes and Consequences, (Chicago: University of Chicago Press for the NBER).

King, M. and S.B. Wadhwani (1990), "Transmission of volatility between stock markets", Review of Financial Studies, 3(1), 5-33.

King, M., E. Sentana and S.B. Wadhwani (1994), "Volatility and links between national stock markets", Econometrica, 62(4), 901-933. 
Pericoli, M. and Sbracia, M. (2003), "A Primer on Financial Contagion", Journal of Economic Surveys, 17 (4), 571-608.

Rigobon, R. (2002), "Currency Crises and Contagion: an introduction", Journal of Development Economics, 69(2), 307-313.

Rigobon, R. (2003), "On the measurement of the international propagation of shocks: is the transmission stable?", Journal of International Economics, 61(2), 261-283.

Rigobon, R. (2004), "Identification through heteroscedasticity", Review of Economics and Statistics, 85(4), 777-792.

Sentana, E. (1992), "Identification of multivariate conditionally heteroscedastic factor models", LSE, FMG Discussion Paper no. 139.

Sentana, E. and Fiorentini, G. (2001), "Identification, estimation and testing of conditionally heteroscedastic factor models", Journal of Econometrics, 102(1), 143-164. 
Table 1: Developed countries exposure to East Asian emerging markets

\begin{tabular}{|c|c|c|c|c|}
\hline GER & Q4 1996 & Q2 1997 & Q4 1997 & Q2 1998 \\
\hline KOREA & 9977 & 10968 & 9849 & 8678 \\
\hline THAI & 6914 & 8295 & 6463 & 5609 \\
\hline MAL & 3857 & 6627 & 7839 & 5479 \\
\hline INDO & 5508 & 5920 & 6367 & 6084 \\
\hline FRA & Q4 1996 & Q2 1997 & Q4 1997 & Q2 1998 \\
\hline KOREA & 9370 & 11349 & 11861 & 8440 \\
\hline THAI & 4642 & 5439 & 5026 & 4111 \\
\hline MAL & 2643 & 2962 & 2885 & 2391 \\
\hline INDO & 4828 & 5144 & 4950 & 4134 \\
\hline JAP & Q4 1996 & Q2 1997 & Q4 1997 & Q2 1998 \\
\hline KOREA & 25722 & 25160 & 21290 & 20223 \\
\hline THAI & 39475 & 39694 & 35081 & 28352 \\
\hline MAL & 9172 & 11783 & 9276 & 8535 \\
\hline INDO & 23453 & 24449 & 22834 & 19512 \\
\hline UK & Q4 1996 & Q2 1997 & Q4 1997 & Q2 1998 \\
\hline KOREA & 6203 & 6724 & 7803 & 6249 \\
\hline THAI & 4660 & 2818 & 2361 & 2088 \\
\hline MAL & 1417 & 2011 & 2014 & 1613 \\
\hline INDO & 3834 & 4332 & 4492 & 3967 \\
\hline
\end{tabular}

Note: billions of US dollars. Source: BIS (1999). 
Table 2: Wald test for contagion

\begin{tabular}{|l|c|c|c|c|}
\hline & FRANCE & GERMANY & JAPAN & UK \\
\hline INDONESIA & $\begin{array}{c}\mathbf{2 7 . 3 2} \\
(10.98)\end{array}$ & $\begin{array}{c}\mathbf{1 9 . 7 2} \\
(10.10)\end{array}$ & $\begin{array}{c}\mathbf{2 4 . 0 1} \\
\mathbf{( 7 . 4 5 )}\end{array}$ & $\begin{array}{c}\mathbf{2 0 . 1 5} \\
(11.29)\end{array}$ \\
\hline MALAYSIA & $\begin{array}{c}5.57 \\
(11.12)\end{array}$ & $\begin{array}{c}\mathbf{2 3 . 2 8} \\
(12.08)\end{array}$ & $\begin{array}{c}\mathbf{2 0 . 0 2} \\
(12.49)\end{array}$ & $\begin{array}{c}\mathbf{2 1 . 1 0} \\
(13.67)\end{array}$ \\
\hline SOUTH & $\mathbf{6 6 . 6 3}$ & 2.14 & $\mathbf{1 9 . 8 2}$ & 9.21 \\
KOREA & $(13.93)$ & $(11.54)$ & $\mathbf{( 8 . 9 2 )}$ & $(10.26)$ \\
\hline THAILAND & $\mathbf{3 2 . 2 5}$ & 12.10 & $\mathbf{2 6 . 9 9}$ & $\mathbf{6 5 . 4 9}$ \\
& $\mathbf{( 7 . 0 2 )}$ & $(12.41)$ & $\mathbf{( 7 . 6 3 )}$ & $\mathbf{( 1 2 . 9 7 )}$ \\
\hline
\end{tabular}

Note: The variables in each cell are the Wald Test statistics under the null $\mathrm{H}_{0}$ : $\alpha_{1}=\beta_{1}=0$. The corresponding bootstrapped $95 \%$ empirical critical values are in parentheses. Numbers in bold indicate evidence of contagion. 
Table 3: Crisis period estimation

\begin{tabular}{|c|c|c|c|c|}
\hline & FRANCE & GERMANY & JAPAN & UK \\
\hline INDONESIA & $\begin{array}{c}\text { 0.96 }\{\text { Dec97\} } \\
(4.99 ; 2.19) \\
0.15 \\
(2.48 ; 2.56)\end{array}$ & $\begin{array}{c}\mathbf{0 . 9 2}\{\text { Feb98\} } \\
(4.43 ; 2.18) \\
0.17 \\
(1.45 ; 2.01)\end{array}$ & $\begin{array}{c}\mathbf{1 . 1 5} \text { \{Sept97\} } \\
(4.89 ; 2.31) \\
0.02 \\
(0.55 ; 2.01)\end{array}$ & $\begin{array}{c}0.13 \\
(1.33 ; 2.35) \\
\\
\mathbf{0 . 8 8}\{\text { Oct97\} } \\
(2.62 ; 1.60)\end{array}$ \\
\hline MALAYSIA & & $\begin{array}{c}-0.14 \\
(-0.48 ; 3.15) \\
\\
-0.11 \\
(-4.82 ; 2.06) \\
\end{array}$ & $\begin{array}{c}\text { 1.33 } \text { \{Sept97\} } \\
(3.78 ; 2.74) \\
-0.16 \\
(-2.05 ; 2.15) \\
\end{array}$ & $\begin{array}{c}-0.01 \\
(-0.05 ; 3.39) \\
-0.10 \\
(-4.32 ; 2.76) \\
\end{array}$ \\
\hline $\begin{array}{l}\text { SOUTH } \\
\text { KOREA }\end{array}$ & $\begin{array}{c}\mathbf{0 . 4 7} \text { \{Apr98\} } \\
(2.16 ; 1.71) \\
\text { 0.14 }\{\text { Apr98\} } \\
(8.15 ; 2.94)\end{array}$ & & $\begin{array}{c}\mathbf{0 . 9 0} \text { \{0ct97\} } \\
(4.45 ; 2.18) \\
0.08 \\
(1.31 ; 2.04)\end{array}$ & \\
\hline THAILAND & \begin{tabular}{|c}
0.65 \\
$(1.85 ; 2.12)$ \\
\\
0.19 $\{$ Jul97\} \\
$(5.67 ; 2.01)$
\end{tabular} & & $\begin{array}{c}\mathbf{1 . 2 0}\{\text { Jul97\} } \\
(4.93 ; 1.57) \\
0.17 \\
(2.13 ; 2.28)\end{array}$ & $\begin{array}{c}0.49 \\
(1.39 ; 2.32) \\
\\
\text { 0.18 }\{\text { Apr98\} } \\
(8.08 ; 2.68)\end{array}$ \\
\hline
\end{tabular}

Note: The point estimates for $\alpha_{1}$ and $\beta_{1}$ are reported in the top and bottom panel, respectively, of each cell. Numbers in brackets give the t-ratios and the corresponding bootstrapped $95 \%$ critical values. The contagion dates are in bold and in curly brackets. 